\title{
Investigating Sustainability Stages in the Workplace
}

\author{
Ray Yun ${ }^{1}$, Peter Scupelli ${ }^{3}$, Azizan Aziz ${ }^{2}$, Bertrand Lasternas ${ }^{2}$, \\ Vivian Loftness ${ }^{2}$, and Nana Wilberforce ${ }^{4}$ \\ ${ }^{1}$ Computational Design, School of Architecture \\ ${ }^{2}$ Building Performance and Diagnostics, School of Architecture \\ ${ }^{3}$ School of Design, Carnegie Mellon University, Pittsburgh, PA, United States \\ \{ryun, scupelli, azizan, blastern, loftness\} @ cmu.edu \\ ${ }^{4}$ Realty Services, PNC Bank, Pittsburgh, PA, United States \\ nana.wilberforce@pnc.com
}

\begin{abstract}
Prior research on stage-based, behavior-change models investigated intervention effectiveness for stress management, smoking cessation, weight management, adherence to lipid-lowering drugs and the like. Few sustainability centered studies identify people's stage-based levels for energy use reduction or sustainability. In this paper, we investigate sustainability stages with measured behavior and eco-awareness scores based on Geller's behavior change model. Eighty office employees were assigned to one of four experimental energy dashboard conditions: (a) no energy dashboard; (b) feedback only; (c) feedback and manual on/off controls; and (d) feedback, manual on/off controls, and on/off calendaring. We measured with pre-post surveys change in sustainability levels, energy efficiency discussions frequency, and organizational efforts to understand the work environment. We found that the dashboard with feedback, controls, and on/off calendaring were significantly associated with reported greater energy saving behavior compared to no energy dashboards, and dashboards with fewer features (i.e., feedback only; feedback and on/off control).
\end{abstract}

Keywords: behavior change, stages, sustainability, energy dashboard, persuasive system, workplace, organization.

\section{Introduction}

Behavior-change researchers develop strategies and investigate intervention effectiveness in terms of improving health, decreasing environmental degradation and other benefits. There are a number of theories and approaches that explain the causes, processes, methods and barriers that influence behavioral change [e.g., 1, 3, 4, 5]. Among other theories, stage-based, behavior-change models are widely employed to explain the process of behavior change. The main idea is that behavior change occurs by progressing through a series of stages. For example in healthcare, the Transtheoretical Model (TTM), also known as the Stages of Change Model, involves five stages (i.e., pre-contemplation, contemplation, planning, action, maintenance) [10]. In health related studies on stress management, smoking cessation, weight 
management, adherence to lipid-lowering drugs and the like, surveys were used to identify study participants' stage of change [e.g., 18, 19]. Unfortunately, there is limited research on stages of change for sustainability related behavior, notable exceptions include [6]. This study investigates the measurement of sustainability-level changes in combination with different experimental interventions. In the home environment, wasted energy usually bears financial costs for the energy consumers. Instead in the large office environments typically office energy consumers are unaffected financially by the energy they use. We target office workers in this study, to investigate whether lack of direct financial incentives limits pro-environmental behavior in work environments.

\section{Behavior Change Models for Sustainability}

Previous research [8] and Valente [14] review various behavior change models and five stage-based models were found - TTM [10], Diffusion of Innovations [16], Piotrow's Steps to Behavior change [9], Mcguire's Hierarchy of Effects [17] and Geller's model [11]. Table 1 illustrates the comparison of the stages of the behavior change models. TTM explains the process of health-behavior change in five stages (Precontemplation - Contemplation - Preparation - Action - Maintenance), Rogers Diffusion theory demonstrates five stages in the adoption process (Awareness Persuasion - Decision - Implementation - Confirmation). Piotrow et al. and McGuire expanded the stages of behavior change into more specific hierarchy to health promotion evaluation as illustrated in Table 1. Geller's model demonstrates four performer behavior stages (unconscious incompetence, conscious incompetence, conscious competence, unconscious competence).

These models contain a similar behavior change process. For example, people do not perform the target behavior at first, because they do not know the value of it. If they realize the value, they move onto the next stage. Even if people know the value of the behavior change, they may not act on that knowledge immediately because they need time to process and assimilate the new information before making decisions. After they decide to change, people perform the target behavior and reach the next stage. The last stage is where people continuously perform the target behavior to the point where it has become habitual.

There are three distinctions among the models. First Diffusion theory [12] was initially derived from studies on knowledge adoption whereas others focus on behavior adaption. Second, TTM model was initially developed to understand the process of quitting bad habits (e.g., quitting smoking), however the rest rather focus on the process of adopting a new behavior [14]. Third, the first four models are associated with health behavior change whereas the last one focuses on environmental behavior change. The Geller's model clearly and simply explains the stages of behavior change and more importantly, it focuses on sustainability, therefore we employ his model for our study to investigate an individual's sustainability level. One of the limitations of Geller's model is that it focuses on the level of the individual, whereas in the office environment individual behavior is shaped by a larger context that includes at least the workgroup and organization. The Process-Person-ContextTime Model (PPCT) by Bronfenbrenner includes such dimensions [1]. 
Table 1. Comparison of Stages of Behavior Change (Adapted from Valente [14])

\begin{tabular}{|c|c|c|c|c|}
\hline $\begin{array}{l}\text { Diffusion of } \\
\text { Innovations (Rogers, } \\
1995)\end{array}$ & $\begin{array}{l}\text { Hierarchy of effects } \\
\text { (Mcguire, 1989) }\end{array}$ & $\begin{array}{l}\text { Steps to behavior } \\
\text { change } \\
\text { (Piotrow et al., } \\
1997 \text { ) }\end{array}$ & $\begin{array}{l}\text { TTM } \\
\text { (Prochaska et al. } \\
\text { 1992) }\end{array}$ & $\begin{array}{l}\text { Behavior Change for } \\
\text { Sustainability } \\
\text { Geller, 2002) }\end{array}$ \\
\hline & & & 1. Pre-contemplation & $\begin{array}{l}\text { 1. Unconscious } \\
\text { incompetence }\end{array}$ \\
\hline 1. Knowledge & $\begin{array}{l}\text { 1. Recalling message } \\
\text { 2. Liking message } \\
3 \text {. Comprehending } \\
\text { message } \\
\text { 4. Knowledge of } \\
\text { behavior } \\
\end{array}$ & $\begin{array}{l}\text { 1.Recalls message } \\
\text { 2.Understands topic } \\
\text { 3.Can name source of } \\
\text { supply }\end{array}$ & 2. Contemplation & $\begin{array}{l}\text { 2. Conscious } \\
\text { incompetence }\end{array}$ \\
\hline 2. Persuasion & $\begin{array}{l}\text { 5. Skill acquisition } \\
\text { 6. Yielding to it } \\
\text { 7. Memory storage of } \\
\text { content }\end{array}$ & $\begin{array}{l}\text { 4. Responds favorably } \\
\text { 5. Discusses with } \\
\text { friends/family } \\
6 \text {. Thinks others } \\
\text { approve } \\
\text { 7. Approves oneself } \\
\text { 8. Recognizes that } \\
\text { innovation meets need }\end{array}$ & & \\
\hline 3. Decision & $\begin{array}{l}\text { 8. Information search } \\
\text { and retrieval } \\
\text { 9. Deciding on basis of } \\
\text { retrieval }\end{array}$ & $\begin{array}{l}\text { 9. Intends to consult a } \\
\text { provider } \\
\text { 10. Intends to adopt } \\
\text { 11. Go to provider }\end{array}$ & 3. Preparation & \\
\hline 4. Trial & $\begin{array}{l}\text { 10. Behaving in } \\
\text { accordance with } \\
\text { decision }\end{array}$ & $\begin{array}{l}\text { 12. Initiates use } \\
\text { 13. Continues use }\end{array}$ & 4. Action & $\begin{array}{l}\text { 3. Conscious } \\
\text { competence }\end{array}$ \\
\hline 5. Adoption & $\begin{array}{l}\text { 11. Reinforcement of } \\
\text { desired acts } \\
\text { 12. Post-behavior } \\
\text { consolidation }\end{array}$ & $\begin{array}{l}\text { 14. Experiences } \\
\text { benefits } \\
\text { 15. Advocates that } \\
\text { others practice behavior } \\
\text { change } \\
\text { 16. Supports practice in } \\
\text { the community }\end{array}$ & 5. Maintenance & $\begin{array}{l}\text { 4. Unconscious } \\
\text { competence }\end{array}$ \\
\hline
\end{tabular}

\section{Measurement of the Stages}

As mentioned earlier, we found few studies that assess sustainability stages. Mair et al. [6] developed a survey that asks twenty-nine questions on how often they carry out certain sustainable practices such as commuting by bicycle, recycling and cold-water wash. The response options provided were: never - sometimes - often - regularly always. Scores were calculated per person and classified to each TTM stage. When this approach was reviewed, three issues were found. First their survey covered a wide range of sustainable practices (transportation, energy, water use, waste management, etc.) and they were equally weighted. We contend that people may be committed to one aspect of sustainability but not others. Hence, TTM stages may vary by sustainability area practice. For example, one may be a committed recycler at home but commute by car to work. Second, the TTM model was applied to sustainability, whereas typically it is used for health behavior change. In other words, there may be a requirement for modifications in order for the model to apply to sustainable behavior change. Third, the stages were defined based on the level of practice (e.g., Pre-contemplation: 26-52, 
Contemplation/preparation: 52-78, Action: 78-104, Maintenance: 104-130), despite the fact that this does not distinguish knowledge, awareness, planning, and behavior. In other words, one may be very informed about sustainability issues and do very little to put into action such knowledge.

Our study refined Mair et al.'s approach to complement the limits as follows. First, we narrowed the sustainability domain to plug-load management for desktop technology in the workplace, second, we employed Geller's model because it was developed specifically for sustainability, and third, instead of assigning each person to a specific stage, we mapped awareness and behavior scores in scatter plot to describe one's stage. The survey questions we developed are listed in Table 2.

Table 2. Survey question examples

\begin{tabular}{|c|c|}
\hline Question examples & Option examples \\
\hline $\begin{array}{l}\text { Q1. How often do you turn off or unplug your: } \\
\text { - } \quad \text { Computer when not in use on nights and weekends? } \\
\text { - } \quad \text { Computer monitor when not in use on nights and weekends? } \\
\text { - } \quad \text { Task light (lamp, underbin light) when not in use? } \\
\text { - } \quad \text { Office phone on nights and weekends? }\end{array}$ & $\begin{array}{l}\text { a) Never (1) } \\
\text { b) Rarely (2) } \\
\text { c) Sometimes (3) } \\
\text { d) Often (4) } \\
\text { e) Always (5) } \\
\text { f) Do not know (0) }\end{array}$ \\
\hline $\begin{array}{l}\text { Q2. Have you: } \\
\quad \text { Adjusted power settings (e.g., to power saver mode) for the } \\
\quad \text { computer you are using at work? } \\
\quad \text { Adjusted brightness settings for your computer monitor at } \\
\text { work? }\end{array}$ & $\begin{array}{l}\text { a) Yes (5) } \\
\text { b) No (1) } \\
\text { c) Do not know (0) } \\
\text { d) Not applicable }\end{array}$ \\
\hline 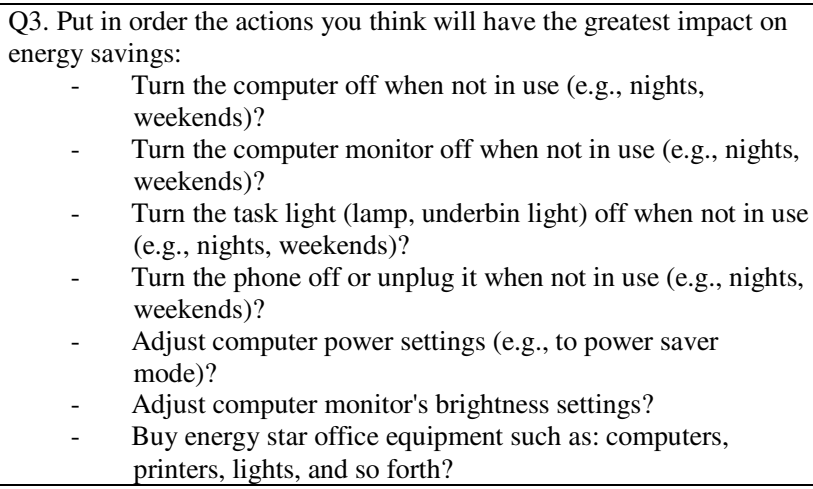 & \\
\hline $\begin{array}{l}\text { Q4. Have you: } \\
\quad-\quad \text { Discussed energy usage/saving in your work group? }\end{array}$ & $\begin{array}{l}\text { a) Yes (5) } \\
\text { b) No (1) } \\
\text { c) Do not know (0) } \\
\text { d) Not applicable }\end{array}$ \\
\hline $\begin{array}{l}\text { Q5. How often does your organization: } \\
\text { - } \quad \text { Provide workers with very energy efficient products (e.g., } \\
\text { computers, displays, lights)? } \\
\text { - } \quad \text { Encourage workers to reduce energy use in the office? }\end{array}$ & $\begin{array}{l}\text { a) Never (1) } \\
\text { b) Rarely (2) } \\
\text { c) Sometimes (3) } \\
\text { d) Often (4) } \\
\text { e) Always (5) } \\
\text { f) Do not know (0) }\end{array}$ \\
\hline
\end{tabular}


These questions were developed based on the PIER's report [12] which suggests the most effective methods of plug-load management for the office environment. Question one and two identify the frequency with which users select pro-environmental behavior in terms of the use of office appliances. Question three investigates user understanding of their own energy consumption at work. Questions four and five help understanding users' work environment and organizational culture [2].

\section{Method}

A field study has been designed and implemented at a large office building to investigate the proposed "sustainability stages" described above. Eighty employees in one department (realty services) were recruited. They were randomly assigned to four groups and the different interventions (different energy dashboards equipped with different features) were given to each group (Figure 1, [13]). The survey above was conducted twice - right before and one month after the interventions were given to each group.

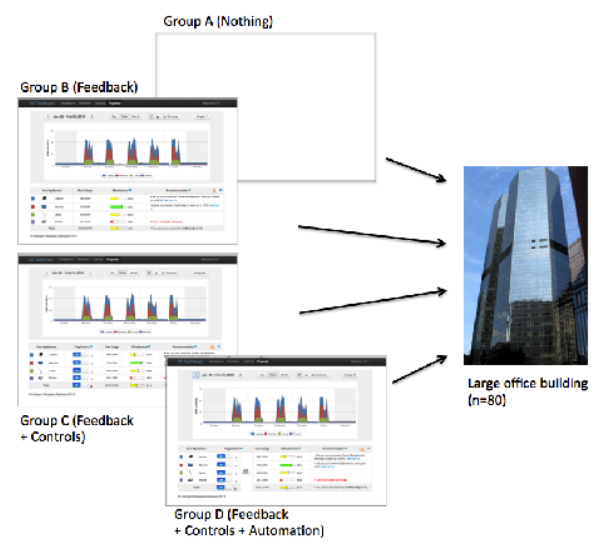

Fig. 1. Energy dashboard interventions: Nothing for Group A, feedback only for Group B, feedback and controls for Group C, and feedback, control and automated control for Group D. See [13] for more details on the dashboard system.

To quantify behavior change from the survey, a certain score number value has been assigned to each option in table 1 . Those numbers are summed per group and averaged. To quantify the awareness change, correct answers from questions \#3 were counted and averaged. The correctness of the answers was evaluated based on the energy usage data collected from the smart meters installed for individual users.

\section{$5 \quad$ Preliminary Results}

As noted above, eighty participants were recruited for this study. Sixty-three participated in the pre intervention survey (Group A:16, B:17, C:14, D:16) and fifty- 
one participated in the post intervention survey (Group A:13, B:17, C:10, D:11). Age and gender were not collected due to the company policy. To simply present the comparative data, all results have been converted to percentages.

Based on the survey responses, behavior change was measured as follows. (Figure 2) The $y$-axis is the average score percentage calculated from each group's response to questions one and two. For example, if a person answered to always (5) to all Q1 questions and yes (5) to all Q2 questions, his or her behavior score is 30 and is converted to 100. Seven weeks after the energy dashboard was given, Group A's behavior score was increased only $5.7 \%$ but in Group B, C and D score increased by $26.9 \%, 36.8 \%$, and $51.9 \%$ respectively. The pre-post measures for Group D (feedback, on/off controls, automation) were significantly different $[\mathrm{t}(23)=3.4, \mathrm{p}<0.002]$. For post intervention Group D (feedback, on/off controls, automation) was significantly different than Group A (no dashboard), B (feedback only), and C (feedback and on/off controls) $[\mathrm{F}(3,46)=4.99, \mathrm{p}<0.005]$. Group $\mathrm{A}$ (no dashboard) and D (feedback, on/off controls, automation) were statistically different $[\mathrm{t}(21)=3.93, \mathrm{p}<0.001$; Group B (feedback only) and $\mathrm{D}$ (feedback, on/off controls, automation) were significantly different $[\mathrm{t}(25)=2.90$, $\mathrm{p}<0.01$ ]; Group C (feedback and on/off controls) and D (feedback, on/off controls, automation) trended towards statistical significance $[\mathrm{t}(18)=1.82, \mathrm{p}<0.08]$.

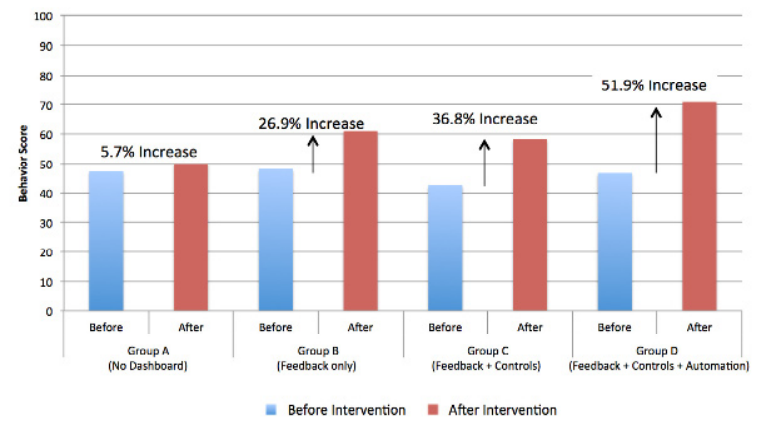

Fig. 2. Behavior change measured with survey responses for respondents' behavioral effort based on their answer to questions one and two (Pre $\mathrm{N}=63$; Post $\mathrm{N}=51$ )

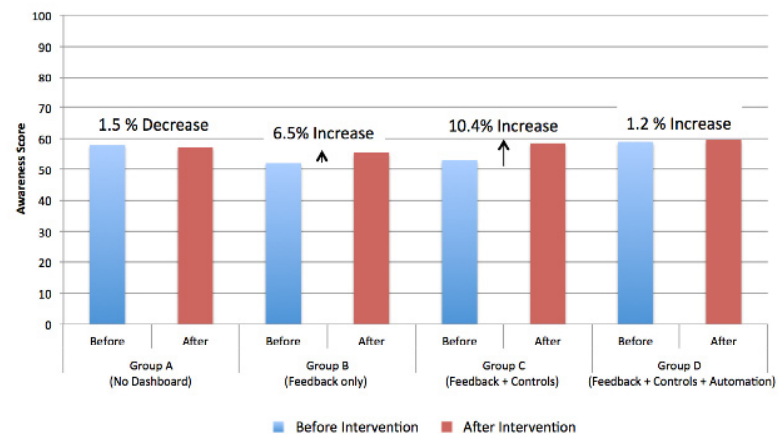

Fig. 3. Awareness changes measured with seven questions on the impact of energy savings (Pre $\mathrm{N}=63$; Post $\mathrm{N}=51$ ) 
Awareness change between before and after the intervention was also measured using the survey. The $y$-axis in Figure 3 represents the average correctness of each group's response to the question three (impact on energy savings). For example, if a person answered correctly to all seven questions in Q3, his or her correctness represented as $100 \%$. Awareness change from Group A and Group D was measured at less than $1.5 \%$, but Group B and C showed a $6.5 \%$ and a $10.4 \%$ increase, respectively. We found no statistically significant differences of the groups pre-post or between groups.

The behavior and awareness was measured pre and post intervention for each experimental group. Figure 4 shows the average sustainability behavior and awareness. As mentioned earlier, behavior change stage-based models (e.g., Geller's model) mainly consist of two dimensions - awareness and behavior. People in the first stage who don't have knowledge and don't perform the pro-environmental behavior can be positioned at the lower left corner on the chart (unconscious incompetence, pink). Once they understand the knowledge but still think of changing their behavior, they are located at the upper left corner on the chart because their awareness increased (conscious incompetence, orange). If the pro-environmental behavior starts to be performed and its frequency increases, people on the chart start to move to right hand side. If this behavior is performed fluently, they are positioned close to the end of the right hand side. The last stage is Unconscious competence. This is when people conduct the behavior automatically without conscious effort. It is located not at the lower-right corner, but at the upper-right because Geller [8] argued once the knowledge is gained, it is not likely to be lost and go back to the beginning stage where there is no knowledge. Also, the last stage contains the word "unconscious" because the behavior already became a habit and performed "unconsciously". It is used differently from the first stage where people are "unconscious"(unaware) of the value of behavior change. The stages in the chart (Figure 4) are overlapped each other because based on Valente [14], behavior stages are not mutually exclusive.

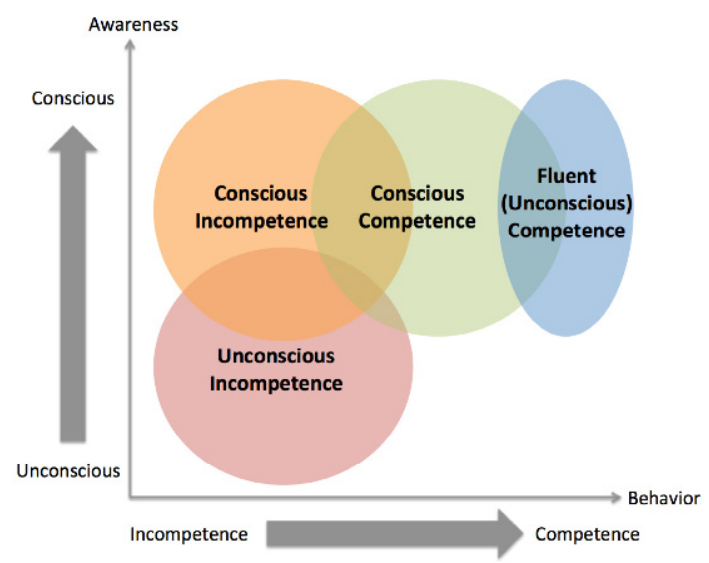

Fig. 4. Sustainability level based on the measured behavior and awareness 

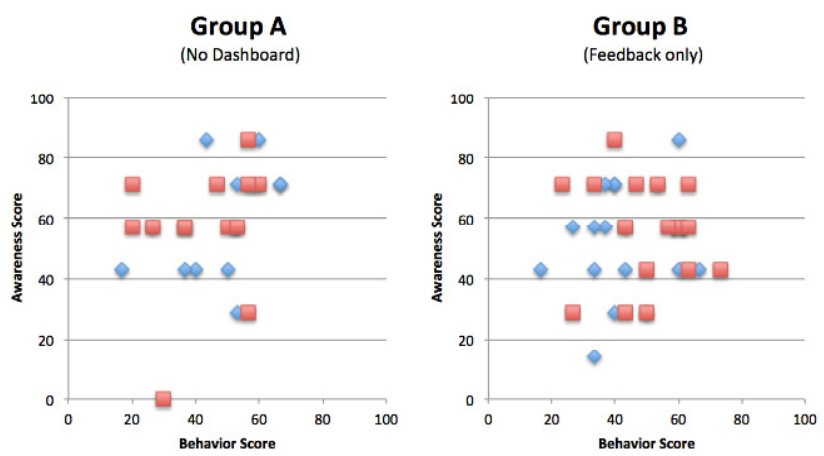

Group C

(Feedback + Controls)

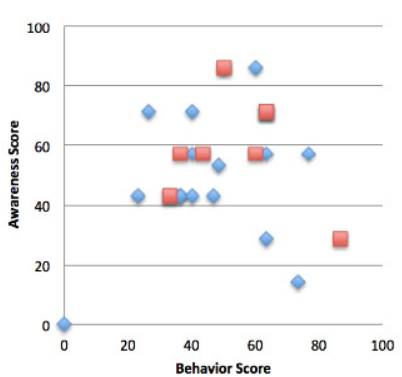

Group D

(Feedback + Controls + Automation)

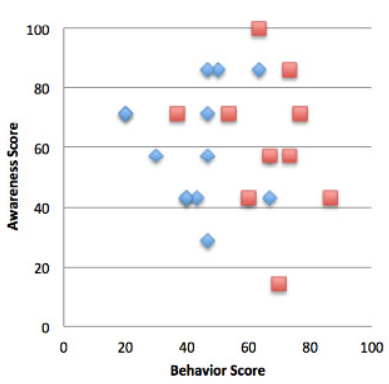

Before Intervention

After Intervention

Fig. 5. Sustainability level changes measured for awareness and behavior

Using the behavior and awareness percentage measured from the survey, each group's sustainability level can be presented as follows. Based on the Figure 5, the majority of the results from our participants in four groups are positioned in the second stage (conscious incompetence) and the third stage (conscious competence) areas of the graph before the intervention is given (blue diamond in Figure 5). Seven weeks after the intervention, when the follow-up survey was given, the results show that Group A remained virtually unchanged, while Group B moved to right, Group C moved mostly to the upper-right with some in the lower right, and Group D moved to the right even further (but up-down direction was random).

In addition to behavior and awareness, questions focused on discussion frequency and the company's effort related to energy conservation were also asked on the survey. Figure 6 illustrates the discussion frequency with the Y-axis representing the average discussion frequency of each group. For example, if a person answered "yes" to the question 4, the frequency becomes 100 percent. All groups reported that their discussion frequency was increased after the intervention (A: $19.4 \%, \mathrm{~B}: 77.5 \%, \mathrm{C}$ : $56.5 \%$, D: $22.7 \%$ ). It was found that Group A and D had relatively small frequency increases compared to Group B and C. 


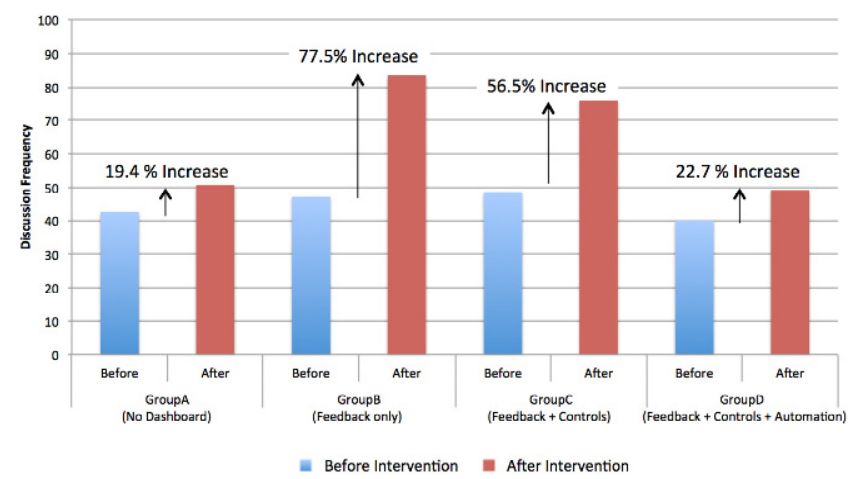

Fig. 6. Discussion of energy usage and savings in workgroup measured pre-post with one survey question (Pre $\mathrm{N}=63$; Post $\mathrm{N}=51$ )

To investigate the organization's effort, at providing energy efficient products and increasing encouraging energy saving employee behavior, those two specific inquiries were included as part of question five. The first part of question five asked employees directly whether the company provides energy efficient products for their use. The second part of question five asked participants whether the company encourages them to save energy. Participants generally reported positively. Only $9 \%$ of people surveyed responded that their organization "never" or "rarely" provided energy efficient products and just $6 \%$ responded that their organization "never" or "rarely" encouraged them to save energy. After the dashboard intervention was given, results from the two questions were similar to each other (Figure 7 and 8). On both questions, Group D showed the biggest increase (Q5-1: 42\%, Q5-2: 22.9\%), Group C showed the second-biggest (Q5-1: 24\%, Q5-2: 10.2\%), and Group B showed the third-biggest (Q5-1: 13\%, Q5-2: 3.1\%). Participants might have thought that as more technologically advanced systems were given, the more effort was made by the organization.

The pre-post intervention survey responses to the survey question about discussion on energy usage and savings for Group B (feedback only) were significantly different $[\mathrm{t}(31)=3.97, \mathrm{p}<0.001]$. The pre-post intervention survey responses to the same question for Group $\mathrm{C}$ (feedback and on/off controls) trended towards significant differ ences $[\mathrm{t}(22)=1.69, \mathrm{p}<0.10]$. The post intervention survey responses to the survey question about discussion about energy usage and savings in the four groups were significantly different $[\mathrm{F}(3,45)=3.84, \mathrm{p}<0.02]$. Group A (no dashboard) and B (feedback only) were statistically different $[\mathrm{t}(27)=3.54, \mathrm{p}<0.001$; Group B (feedback only) and $\mathrm{D}$ (feedback, on/off controls, automation) were significantly different $[\mathrm{t}(24)=2.76, \mathrm{p}<0.01$. 


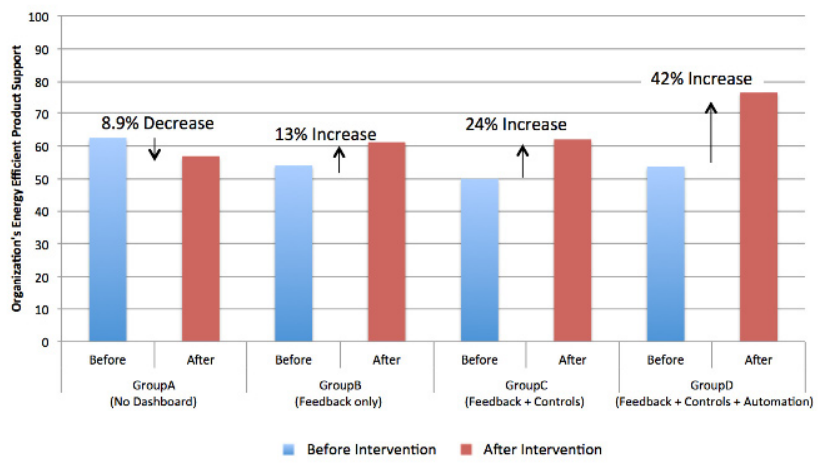

Fig. 7. Company's effort on providing energy efficient product from Group A to Group D (Pre $\mathrm{N}=63$; Post $\mathrm{N}=51$ )

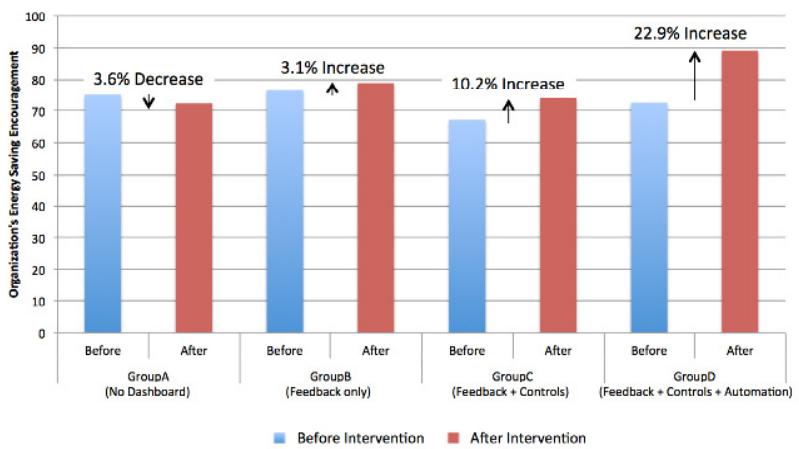

Fig. 8. Company's effort on encouraging office workers from Group A to Group D (Pre N=63; Post $\mathrm{N}=51$ )

\section{Discussion}

This section discusses the issues the team had during the implementation of our study.

First, in Figure 2, the result from each group showed that their average behavior score was increased as follows: Group A 5.7\%, Group B 26.9\%, Group C 36.8\%, and Group D $51.9 \%$. These results indicate the feedback that as more advanced features were equipped as part of the user dashboard, the greater the positive percentage change to the behavior score. The behavior score was measured from each users voluntary report to the survey, not from using any sensors. To supplement the survey result, smart electricity meters were used to measure each individual participant's energy consumption. In this field study, using the smart meters for verification, these quantitative measurements showed the following results in terms of energy savings: Group A 3.6\%, Group B 9.0\%, Group C 20.2\%, and Group D 35.4\%. These results support our survey results. 
Second, we demonstrated that the scatter plots show the individual groups sustainability level change based on their behavior and awareness. The stage based behavior change models define the stages in term of whether a person knows the value of the behavior change, whether a person performs the target behavior, and whether the changed behavior is fluently performed. To assess a person's stage, those questions should be answered as yes or no, but in reality it is not simple to answer that way. Instead of showing how many people in the group change their stages, our approach is to display each users status in the scatter plots. The movement of dots overall indicates each group's of users sustainability level change before and after the intervention. Thus, overall performance of the company toward increasing sustainability attainment can be better understood.

Third, we created Group A as a control group. As shown in Figures 2, 5 and 6, this group may be influenced by talking to other dashboard users because all the participants were recruited from one department. To deduct the change led by the Hawthorn effect and the seasonal effect from each group, the difference value made in Group A, in terms of percent change, can be subtracted from each group.

Finally, due to the limited sample size, there may have not been enough statistical power to show all significant relationships. Limited responses in the second post survey further may have reduced the sample. Another limitation regards the accuracy and reliability of survey measures. The corporate sponsor limited the total number of questions we could include in the survey. More questions would have allowed us to explore a broader range of scales seeking to demonstrate and document a more reliable measure of behavior and awareness change.

\section{Summary}

This paper discusses investigating sustainability stages on plug-load management in the office environment. The authors developed a survey based on Geller's behavior change model, measured participants behavior and awareness scores, and displayed their sustainability level on the scatter plots. It was found that as more advanced systems were provided, more energy savings (behavior change) were realized and the more vigorous movement towards the last stage (unconscious incompetence) was indicated in the scatter plot. In two months the research team will remove the interventions (energy dashboards) from the participant's work environment and conduct the survey again to investigate if their sustainability change can last persistently without the interventions. If that result is displayed in the scatter plots together with the current findings, it will show a good overview of the sustainability stages in operation before intervention, after intervention, and after the intervention is removed.

Acknowledgments. This study is supported by the Energy Efficient Buildings Hub Consortium (EEBHub.org, a U.S. DOE Innovation Hub, Subtask 6.4) under the U.S. Department of Energy Award Number EE0004261. We would like to thank all the participants who volunteered to take part in this study and Christopher Leininger who contributed to the editing of this paper. 


\section{References}

1. Fogg, B.J.: Persuasive technology: using computers to change what we think and do. Ubiquity (December 2002), doi:10.1145/763955.763957

2. Bronfenbrenner, U.: Making human beings human: Bioecological perspectives on human development. Sage Publications, Thousand Oaks (2005)

3. Pajares, F.: Overview of social cognitive theory and of self-efficacy (2002)

4. Stern, P.C., Oskamp, S.: Managing scarce environmental resources. In: Stokols, D., Altman, I. (eds.) Handbook of Environmental Psychology, New York, pp. 1043-1088 (1987)

5. Skinner, B.F.: Science and Human Behavior. Simon and Schuster (1965)

6. Mair, J., Laing, J.H.: Encouraging pro-environmental behaviour: the role of sustainabilityfocused events. . Journal of Sustainable Tourism 21(8), 1113-1128 (2013)

7. Riemsma, R.P., Pattenden, J., Bridle, C., Sowden, A.J., Mather, L., Watt, I., Walker, A.: A systematic review of the effectiveness of interventions based on a stages-of-change approach to promote individual behaviour change in health care settings. Health Technology Assessment 6(24), 1-242 (2002)

8. Yun, R., Scupelli, P., Aziz, A., Loftness, V.: Sustainability in the Workplace: Nine Intervention Techniques for Behavior Change. In: Berkovsky, S., Freyne, J. (eds.) PERSUASIVE 2013. LNCS, vol. 7822, pp. 253-265. Springer, Heidelberg (2013)

9. Piotrow, P.T., Kincaid, D.L., Rimon II, J.G., Rinehart, W.: Health communication: lessons from family planning and reproductive health (1997)

10. Prochaska, J.O., Velicer, W.F.: The transtheoretical model of health behavior change. American Journal of Health Promotion 12(1), 38-48 (1997)

11. Geller, E.S.: The challenge of increasing proenvironmental behavior. In: Betchel, R.B., Churchman, A. (eds.) Handbook of Environmental Psychology, New York, pp. 525-540 (2002)

12. Mercier, C., Moorefield, L.: Commercial office plug load savings and assessment: Final report. Produced by ECOVA and Supported Through the California Energy Commission's Public Interest Energy Research Program (2011)

13. Yun, R., Aziz, A., Lasternas, B., Zhang, C., Loftness, V., Scupelli, P., Mo, Y., Zhao, J., Wilberforce, N.: The Design and Evaluation of Intelligent Energy Dashboard for Sustainability in the Workplace. In: Marcus, A. (ed.) Proceedings, HCI International 2014. LNCS, vol. 8519, pp. 605-615. Springer, Heidelberg (2014)

14. Valente, T.W.: Evaluating health promotion programs. Oxford University Press, Oxford (2002)

15. Riemsma, R.P., Pattenden, J., Bridle, C., Sowden, A.J., Mather, L., Watt, I., Walker, A.: A systematic review of the effectiveness of interventions based on a stages-of-change approach to promote individual behaviour change in health care settings. Health Technology Assessment 6(24), 1-242 (2002)

16. Rogers, E.: Diffusion of innovations, 4th edn. The Free Press, New York (1995)

17. McGuire, W.J.: Theoretical foundations of campaigns. In: Rice, R.E., Atkins, C.K. (eds.) Public Communication Campaigns, pp. 39-42. Sage Publications, Newbury Park (1989)

18. Prochaska, J.O., Velicer, W.F., DiClemente, C.C., Fava, J.L.: Measuring the processes of change: Applications to the cessation of smoking. Journal of Consulting and Clinical Psychology 56, 520-528 (1988)

19. O'Connell, D., Velicer, W.F.: A decisional balance measure for weight loss. The International Journal of Addictions 23, 729-750 (1988) 